\title{
EFEKTIVITAS MEDIA POP-UP CARD TERHADAP PENGETAHUAN KESEHATAN GIGI DAN MULUT ANAK USIA 8-9 TAHUN
}

\author{
Rizki Dwi Lestari ${ }^{1}$, Nuzulia Irawati ${ }^{2}$, Murniwati ${ }^{1}$
}

\begin{abstract}
Dental caries is a dental problem that often affects children. One of oral and dental health problems etiology is behavioral or negligence factor to the oral and dental health. This happens due to lack of knowledge about the importance of maintaining oral and dental health, especially in children. Attractive learning media is necessary to improve the knowledge about oral and dental health. The aim of this study is to determine the effectiveness of popup card media toward oral and dental health knowledge of 8-9 years old children. This study used a nonequivalent control group design. Pre-test, treatment and post-test were conducted. Sampling was conducted by random and simple sampling, then the samples were divided into two groups, 23 third grade elementary school students of SDN 23 Echoes Jati Padang were included to the experimental group. This group was taught with oral and dental health education by using pop-up card media and 23 others were included into control group taught with oral and dental health education without pop-up card media. Analysis of the data was conducted using McNemar test. Statistical test results using McNemar test showed a significant increase in the knowledge. Pop-up card media effectively improved the knowledge of experimental group with $p$ value of 0.000 ( $p<0.05)$. Based on the research that has been conducted, it can be concluded that pop-up card media is effective to improve knowledge of 8-9 years old children.
\end{abstract}

Keywords: Children, Pop-up Media, Knowledge

Affiliasi penulis : 1. Fakultas Kedokteran Gigi Universitas Andalas, 2. Fakultas Kedokteran Universitas Andalas.

Korespondensi: Rizki Dwi Lestari , email: rizkidwilestari95@gmail.com Telp: 085268000636

\section{PENDAHULUAN}

Kualitas hidup seseorang di pengaruhi oleh kesehatan, salah satunya adalah kesehatan gigi dan mulut. Dengan kesehatan gigi dan mulut yang baik, beberapa aktivitas seperti berbicara, makan dan bersosialisasi tidak akan terganggu. ${ }^{1}$ Tetapi kenyataannya, sampai saat ini tingkat kesehatan gigi dan mulut masyarakat di Indonesia masih rendah. Hal ini terlihat dari $22,8 \%$ penduduk Indonesia tidak menyikat gigi dan dari $77,2 \%$ yang menyikat gigi, hanya $8,1 \%$ yang menyikat gigi tepat waktu. ${ }^{2}$

Jika kesehatan gigi dan mulut tidak terjaga, maka akan menyebabkan terjadinya karies. Karies merupakan kerusakan gigi yang disebabkan proses penghancuran setempat jaringan kalsifikasi yang dimulai pada bagian permukaan gigi melalui proses dekalsifikasi lapisan email gigi yang diikuti oleh lisis struktur organik secara enzimatis sehingga terbentuk kavitas (lubang) yang bila didiamkan akan menembus email serta dentin dan dapat mengenai bangian pulpa. ${ }^{3}$ 
Karies gigi merupakan salah satu penyakit gigi dan mulut dengan prevalensi yang tinggi. Studi epidemiologi mengenai karies menunjukkan bahwa prevalensi karies meningkat pada negara berkembang. 3 Hasil Riset Kesehatan Dasar tahun 2013, menunjukkan rata-rata indeks DMF-T di Indonesia adalah 4,6 yang artinya rata-rata setiap orang memiliki kerusakan gigi sebanyak 4-5 gigi. ${ }^{4}$ Berdasarkan Riset Dasar tahun 2007, menunjukan bahwa prevalensi nasional karies aktif adalah $43,4 \%$ dan pengalaman karies sebesar 72,1\%. Di Provinsi Sumatera Barat prevalensi karies mencapai 70,6\%.5 Untuk Kota Padang jumlah kejadian karies tahun 2015 adalah 6045 kasus. $^{6}$

Karies gigi tidak hanya pada terjadi pada orang dewasa, tetapi juga dialami oleh anak-anak. Di dunia, 60-90\% anak-anak menderita karies, dan 28,9\% dari jumlah anak di Indonesia usia 5-9 tahun telah mengalami karies. $(3,7)$ Di provinsi Sumatera Barat menunjukkan 21,1\% dari anak usia 5-9 mengalami masalah kesehatan gigi. $^{5} \quad$ Penyebab timbulnya masalah kesehatan gigi dan mulut seperti karies pada anak-anak salah satunya yaitu faktor perilaku atau sikap yang tidak peduli terhadap kesehatan gigi dan mulut, hal tersebut terjadi karena kurangnya pengetahuan anak-anak mengenai pentingnya menjaga kesehatan gigi dan mulut. $\left({ }^{8,9}\right)$ Sebagian besar anak-anak tidak menyadari dan mengetahui pentingnya menjaga kesehatan gigi dan mulut, hal tersebut dikarenakan anak-anak masih sangat bergantung pada orang tua dalam menjaga kesehatan gigi dan mulut. ${ }^{10}$ Pengetahuan tentang pentingnya menjaga kesehatan gigi dan mulut pada anak merupakan faktor penyebab terjadinya karies.8 Terdapat hubungan antara pengetahuan anak tentang karies dengan terjadinya karies, sehingga perlu dilakukan suatu upaya yang bertujuan untuk meningkatkan pengetahuan anak tentang kesehatan gigi dan mulut. ${ }^{11}$

Memberikan pendidikan kesehatan gigi dan mulut pada anak-anak merupakan langkah awal sebagai upaya dalam meningkatkan pengetahuan dan mencegah masalah kesehatan gigi dan mulut. ${ }^{11}$ Pemberian pendidikan kesehatan gigi dan mulut pada anak sekolah dasar sangat penting dilakukan, karena pada masa ini anak- anak mulai mengembangkan kebiasaan yang biasanya cenderung menetap sampai dewasa,12 seperti kebiasaan menjaga kesehatan gigi dan mulut. ${ }^{13}$ Sasaran dari pendidikan kesehatan gigi dan mulut adalah anak-anak usia 8-9 tahun yang duduk di bangku kelas 3 sekolah dasar.(14-16) Usia 8-9 tahun merupakan usia kritis terhadap terjadinya karies gigi permanen, karena masa transisi pergantian gigi susu ke gigi permanen diawali pada usia tersebut dan anak-anak merasakan perubahan pada keadaan giginya, sehingga perlu dilakukan 
pendidikan kesehatan gigi dan mulut pada anak agar anak dapat mengerti bahwa apa yang terjadi pada giginya adalah proses perubahan alami. ${ }^{11}$ Anak-anak juga cenderung mengonsumsi makanan kariogenik seperti permen, kue-kue, dan coklat yang lengket, apabila dikonsumsi berulang nantinya bisa mengakibatkan kerusakan pada gigi anak. $\left({ }^{9,11}\right)$ Pemberian pendidikan tentang kesehatan gigi dan mulut pada usia tersebut anak-anak mengerti untuk menjaga gigi permanen yang tumbuh agar tetap berfungsi dengan baik sampai usia tua. ${ }^{11}$

Anak-anak sebagai sasaran pendidikan memiliki karakteristik tertentu sesuai dengan usia dan perkembangan kognitifnya. Anak dengan usia 8-9 tahun berada dalam tahap perkembangan operasional konkret, yang sudah bisa menggunakan penalaran dalam melakukan pemecahan masalah, $\left.{ }^{14-16}\right)$ maka metode, pendekatan, dan media yang digunakan untuk membantu proses pendidikan pada anak harus disesuaikan agar tujuan pendidikan tercapai dan sasaran dapat memahami materi pendidikan. ${ }^{11,17}$ Selama proses pendidikan tentunya anak-anak tidak terlepas dengan faktor-faktor yang mempengaruhinya dalam belajar. Terdapat faktor internal seperti faktor jasmani, dan psikologi anak, serta faktor eksternal seperti lingkungan, dan kebudayaan. Salah satu faktor yang memiliki peranan dalam proses belajar anak adalah minat anak terhadap materi yang diberikan, yang berpengaruh terhadap hasil dari pemberian pendidikan. ${ }^{2,14,18}$

Media pendidikan dapat digunakan sebagai sarana penunjang, yang dapat merangsang perasaan, pikiran, perhatian, dan minat dari penerima materi. $\left({ }^{12,}{ }^{19-21}\right)$ Penggunaan media yang berisikan gambar-gambar dapat meningkatkan efektivitas pendidikan untuk anak-anak.( ${ }^{11,12,22,23}$ ) Terdapat berbagai bentuk media sebagai alat penunjang pendidikan kesehatan seperti media cetak, elektronik, dan luar ruangan. Media cetak kini telah dikembangkan dalam bentuk yang beragam. ${ }^{20}$

Media Pop-Up card adalah media yang mempunyai unsur tiga dimensi dan gerak. Materi pada media Pop-Up disampaikan dalam bentuk gambar yang menarik karena terdapat bagian yang apabila dibuka dapat bergerak atau berubah bentuk. Media Pop-Up praktis untuk digunakan, mudah dibawa, tampilan berbentuk dua dan tiga dimensi yang dapat menambah semangat belajar anak serta dapat menggunakan media secara mandiri maupun kelompok. Konsep-konsep yang dipelajari dalam media Pop-Up sesuai dengan konsep pembelajaran tematik, yang berarti selama proses pembelajaran berlangsung, anak tidak hanya menghafal konsep atau fakta namun melakukan kegiatan yang menghubungkan konsepkonsep untuk menghasilkan pemahaman yang utuh sehingga konsep yang dipelajari 
akan dipahami secara baik dan tidak mudah dilupakan. $^{24}$

Berdasarkan laporan Dinas Kesehatan Kota Padang tahun 2015 menunjukkan angka kejadian karies di Puskesmas Andalas adalah $13,25 \%$ menjadikan Puskesmas Andalas masuk dalam lima besar kasus karies terbanyak dari 22 Puskesmas di Kota Padang. ${ }^{6}$

Program UKGS pada wilayah kerja Puskesmas Andalas terlihat dari 12.649 orang murid Sekolah Dasar, terdapat 1686 orang murid yang baru mendapatkan penyuluhan kesehatan gigi dan mulut. ${ }^{6}$ Kegiatan UKGS merupakan program yang dilakukan empat kali dalam setahun oleh Puskesmas Andalas. Berdasarkan laporan tahunan Puskesmas Andalas tentang program UKGS tahun 2015 mengenai hasil screening pada 48 sekolah dasar binaan Puskesmas Andalas memperlihatkan bahwa, SDN 24 Jati Gaung merupakan Sekolah Dasar dengan kejadian karies dua terbanyak dengan persentase yaitu $80 \%$ dari jumlah murid yang dilakukan screening. ${ }^{24}$ Pelaksanaan kegiatan UKGS yang dilakukan Puskesmas Andalas pada Sekolah Dasar binaanya, diketahui belum adanya penggunaan media cetak sebagai saranan pemberian penyuluhan atau pembinaan pada program UKGS. Pada sekolah tersebut terlihat adanya masalah kesehatan gigi dan mulut yang cukup tinggi24 Anak-anak usia 8-9 tahun atau kira-kira kelas 3 sekolah dasar yang berada dalam masa transisi tumbuh kembang gigi dan perkembangan kognitif termasuk dalam kriteria inklusi untuk di berikannya pendidikan kesehatan gigi dan mulut. $\left({ }^{10,15,16}\right)$

Berdasarkan tingginya angka karies dan bekuum adanya penggunaan media cetak sebagai sarana pemberian pendidikan kesehatan gigi dan mulut, peneliti tertarik melakuan penelitian tentang efektivitas media Pop-Up card terhadap pengetahuan kesehatan gigi dan mulut anak usia 8-9 tahun di SDN 24 Jati Gaung Kota Padang.

\section{METODE}

Jenis penelitian ini adalah quasi experimental dengan desain penelitian adalah non equivalent control group design. Dilakukan pre test, perlakuan, dan post test pada dua kelompok subjek dengan tingkat kelas yang sama tapi dengan perlakuan yang berbeda ${ }^{25}$

Penelitian ini dilakukan di SDN 24 Jati Gaung Kota Padang pada bulan Februari 2017. Post test dilakukan 20 menit setelah diberikan pendidikan, dengan pertimbangan ingatan manusia segera setelah diberikan informasi adalah sebesar $100 \%$, tetapi setelah 20 menit retensi ingatannya berkurang, yang mampu diingat hanya 58\% dari keseluruhan informasi. ${ }^{26,27}$

Pengambilan sampel pada penelitian ini menggunakan metode Purposive Sampling pada pemilihan lokasi Sekolah Dasar, karena SDN 24 adalah sekolah 
binaan Puskesmas Andalas dengan angka karies tertinggi nomor dua dan belum adanya penggunaan media cetak dalam pemberian penyuluhan kesehatan gigi dan mulut. Karena populasi sampel adalah anak usia 8-9 tahun maka dipilih anak yang sedang duduk di kelas 3 SD yang berjumlah 50 anak. Untuk pemilihan sampel anak kelas 3 di SDN 24 Jati Gaung Kota Padang digunakan metode Total Sampling, dimana jumlah sampel sama dengan populasi. ${ }^{25}$ Sampel di bagi menjadi dua kelompok, yaitu kelompok eksperimen dan kelompok kontrol dengan mempertimbangakan kriteria inklusi dan eksklusi.

Kriteria Inklusi dari penelitian ini adalah keadaan umum baik (fisik dan psikologi), kooperatif, bisa membaca dan mendengar dengan jelas, usia 8-9 tahun. Kriteria Ekslusi adalah tidak hadir pada saat pre test, pemberian pendidikan, dan post test dan tidak mengisi mengembalikan kuisioner. Pada saat hari penelitian, seluruh responden kelas 3 SDN 24 Jati Gaung Kota Padang diberikan lembaran persetujuan mengikuti penelitian. Kemudian, pemilihan sampel berdasarkan kriteria inklusi dan eksklusi, dan sampel di bagi menjadi 2 kelompok, yaitu kelompok eskperimen dan kelompok kontrol. Peneliti melakukan pre test pada responden tentang kesehatan gigi dan mulut. Pengumpulan dilakukan langsung setelah pemberian pre test. Kelompok eksperimen diberikan edukasi kesehatan gigi dan mulut menggunakan media Pop-Up card dan kelompok kontrol diberikan edukasi kesehatan gigi tanpa menggunakan media Pop-Up card. Masingmasing kelompok dilakukan edukasi kesehatan gigi selama 15 menit. Setelah pemberian pendidikan, responden pada masing masing kelompok diberikan waktu bebas, 20 menit kemudian dilakukan post test. Semua hasil post test pada subjek pada masing-masing kelompok dikumpulkan.

\section{HASIL}

Tabel 4.1 Persebaran jumlah responden berdasaarkan kategori tingkat pengetahuan kelompok eksperimen dan kelompok kontroll

\begin{tabular}{ccccc}
\hline $\begin{array}{c}\text { Kategori } \\
\text { Pengetahu } \\
\text { an }\end{array}$ & $\begin{array}{l}\text { Kelompok } \\
\text { Eksperimen }\end{array}$ & \multicolumn{2}{c}{ Kelompok Kontrol } \\
\cline { 2 - 5 } & $\begin{array}{l}\text { Pre } \\
\text { Test }\end{array}$ & $\begin{array}{l}\text { Post } \\
\text { test }\end{array}$ & $\begin{array}{l}\text { Pre } \\
\text { test }\end{array}$ & $\begin{array}{l}\text { Post } \\
\text { test }\end{array}$ \\
\hline Rendah & 14 & 1 & 10 & 4 \\
Tinggi & 9 & 22 & 13 & 19 \\
\hline Jumlah & 23 & 23 & 23 & 23 \\
\hline
\end{tabular}

Tabel diatas menunjukkan responden pada kelompok eksperimen sebelum dilakukan pemberian pendidikan kesehatan gigi dan mulut (pretest) kategori rendah adalah 14 orang dan responden dengan kategori tinggi adalah sembilan orang. Kategori pengetahuan setelah pemberian pendidikan dengan menggunakan media (posttest) yang termasuk kategori rendah adalah satu orang dan yang termasuk ke kategori tinggi 
adalah 22 orang. Jumlah responden dengan kategori rendah pada kelompok kontrol sebelum dilakukan pemberian pendidikan kesehatan gigi dan mulut (pretest) adalah 10 orang dan responden dengan kategori tinggi adalah 13 orang. Pengetahuan setelah pemberian pendidikan dengan menggunakan media (posttest) yang termasuk kategori rendah adalah empat orang dan yang termasuk ke kategori tinggi adalah 19 orang.

Tabel 4.2 Tabel pengetahuan sebelum penyuluhan dan pengetahuan sesudah penyuluhan kelompok eksperimen crosstabulation (Hasil McNemar)

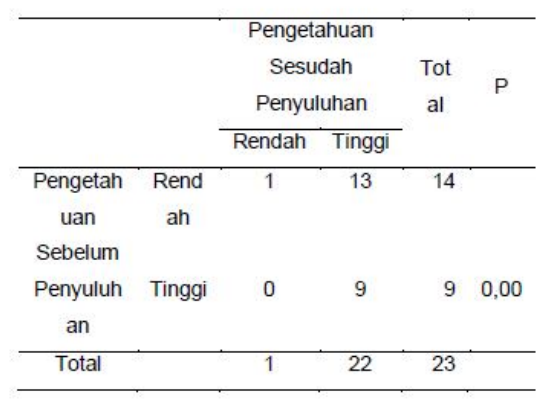

Berdasarkan hasil tabel silang, responden dengan pengetahuan sebelum penyuluhan rendah dan sesudah penyuluhan rendah adalah satu orang. Responden dengan pengetahuan sebelum penyuluhan rendah dan sesudah penyuluhan tinggi adalah 13 orang. Responden dengan tingkat pengetahuan tinggi dan sesudah penyuluhan rendah tidak ada. Responden dengan tingkat penyuluhan tinggi dan sesudah penyuluhan tinggi adalah sembilan orang. Signifikansi pada uji McNemar menunjukkan angka 0,000.
Karena nilai $p<0,05$, terdapat perbedaan yang bermakna dari tingkat pengetahuan pada responden sesudah diberikan perlakuan menggunakan media Pop-Up card pada kelompok eksperimen.

Tabel 4.3 Tabel pengetahuan sebelum penyuluhan dan pengetahuan sesudah penyuluhan kelompok kontrol crosstabulation (Hasil McNemar)

\begin{tabular}{|c|c|c|c|c|c|}
\hline & & \multicolumn{2}{|c|}{$\begin{array}{l}\text { Pengetahuan } \\
\text { Sesudah } \\
\text { Penyuluhan }\end{array}$} & \multirow[t]{2}{*}{$\begin{array}{c}\text { Tot } \\
\text { al }\end{array}$} & \multirow[t]{2}{*}{$P$} \\
\hline & & Rendah & Tinggi & & \\
\hline $\begin{array}{l}\text { Pengetah } \\
\text { uan } \\
\text { Sebelum }\end{array}$ & Rendah & 3 & 7 & 10 & \\
\hline $\begin{array}{l}\text { Penyuluh } \\
\text { an }\end{array}$ & Tinggi & 1 & 12 & 13 & $\begin{array}{r}0,0 \\
7\end{array}$ \\
\hline Total & & 4 & 19 & 23 & \\
\hline
\end{tabular}

Berdasarkan hasil tabel silang, responden dengan pengetahuan sebelum penyuluhan rendah dan sesudah penyuluhan rendah adalah tiga orang. Responden dengan pengetahuan sebelum penyuluhan rendah dan sesudah penyuluhan tinggi adalah tujuh orang. Responden dengan tingkat pengetahuan sebelum penyuluhan tinggi dan sesudah penyuluhan rendah adalah satu orang. Responden dengan tingkat penyuluhan tinggi dan sesudah penyuluhan tinggi adalah 12 orang. Signifikansi pada uji McNemar menunjukkan angka 0,07, karena nilai $\mathrm{p}$ pada kelompok kontrol lebih besar dari 0,05 , sehingga disimpulkan tidak terdapat perbedaan yang bermakna dari tingkat pengetahuan pada responden sesudah diberikan perlakuan tanpa 
menggunakan media Pop-Up card pada kelompok kontrol.

\section{PEMBAHASAN}

Hasil penelitian pada kelompok kontrol menunjukkan terjadi peningkatan pengetahuan kesehatan gigi dan mulut setelah diberikannya pendidikan dengan menggunakan alat bantu media Pop-Up card. Jumlah responden setelah diberikan pendidikan kesehatan gigi dan mulut dengan nilai tinggi pada kelompok eksperimen adalah sebanyak 22 orang dari total jumlah responden 23 orang. Pemberian pendidikan dengan menggunakan media akan mempermudah

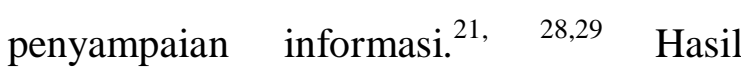
penelitian ini sesuai dengan teori Edgar Dale mengenai teori pembelajaran, yaitu dalam penerimaan

pendidikan menggunakan lebih dari satu indera dapat meningkatkan penyerapan materi oleh responden. $^{33}$ Hal tersebut juga sesuai dengan teori Notoatmodjo bahwa seseorang dapat mempelajari sesuatu lebih baik apabila menggunakan lebih dari satu indera ketika menerima pendidikan. ${ }^{17,23}$ Penggunaan media Pop-Up card sebagai alat bantu dalam memberikan pendidikan kesehatan gigi dan mulut pada anak-anak usia 8-9 tahun di SDN 24 Jati Gaung Kota Padang menunjukkan jumlah responden setelah di berikan pendidikan menggunakan media Pop-Up Card yang mendapatkan kategori nilai tinggi adalah 22 responden dari 23 responden. Peningkatan terjadi pada responden dengan pengetahuan sebelum penyuluhan rendah dan sesudah penyuluhan tinggi sebanyak 13 orang. Responden dengan tingkat penyuluhan tinggi dan sesudah penyuluhan tinggi adalah sembilan orang. Pemberian pendidikan kesehatan gigi dan mulut dengan menggunakan media Pop-Up card masih terdapat responden dengan pengetahuan sebelum penyuluhan rendah dan sesudah penyuluhan rendah sebanyak satu orang.

Hal ini terjadi karena dalam penyerapan informasi pada anak-anak, dipengaruhi oleh faktor internal dan faktor eksternal. Faktor intelegensi termasuk kedalam faktor internal yang mempengaruhi proses penyerapan informasi pembelajaran. $\left({ }^{2,14,23}\right)$ Faktor intelegensi berpengaruh terhadap seberapa banyak orang dapat menangkap informasi dari suatu materi yang diberikan. Responden dengan pengetahuan rendah pada kelompok eksperimen, memiliki tingkat intelegensi dibawah rata-rata, dilihat dari nilai rata-rata rapor responden.

Hasil penelitian pada kelompok kontrol menunjukkan terjadi peningkatan pengetahuan kesehatan gigi dan mulut. Peningkatan terjadi pada responden dengan pengetahuan sebelum penyuluhan rendah dan sesudah penyuluhan tinggi sebanyak tujuh orang. Peningkatan ini terjadi karena peneliti tetap memberikan penyuluhan kepada responden mengenai pendidikan 
kesehatan gigi dan mulut tetapi tanpa menggunakan media Pop-Up card. Tanpa melihat media Pop-Up card, responden mendengar materi yang diberikan, dan dapat menyerap informasi sebesar $20 \% .^{17,30,32}$

Hasil penelitian juga menunjukkan terjadi penurunan tingkat pengetahuan. Responden dengan tingkat pengetahuan tinggi sebelum penyuluhan dan tingkat pengetahuan rendah sesudah penyuluhan adalah satu orang, dan responden dengan tingkat pengetahuan sebelum penyuluhan rendah dan sesudah penyuluhan tetap rendah adalah tiga orang. Hal ini berkaitan dengan teori Edgar Dale yang mengatakan bahwa indera mata memiliki urutan pertama dalam menentukan penyerapan materi pendidikan oleh seseorang yaitu sebesar $75 \%$. Kelompok kontrol dalam penyampaian materi tidak menggunakan media, sehingga responden tidak bisa melihat langsung apa yang disampaikan oleh pemateri dan responden tidak bisa menggambarkan bentuk suatu benda atau pengenalan benda. Pemberian pendidikan menggunakan media, informasi yang diterima lebih besar yaitu 50\% dibandingkan pendidikan tanpa media, informasi yang diterima hanya $20 \%^{17,30,32}$ Responden dengan pengetahuan rendah pada kelompok kontrol, memiliki tingkat intelegensi dibawah rata-rata, dilihat dari nilai rata-rata rapor responden.

\section{KESIMPULAN}

Berdasarkan dari hasil penelitian yang telah dilakukan, dapat disimpulkan bahwa penggunaan media Pop-Up Card efektif terhadap peningkatan pengetahuan kesehatan gigi dan mulut anak usia 8-9 tahun.

\section{KEPUSTAKAAN}

1. Kwan SYL, Petersen PE, Pine CM, Borutta A. Health-promoting schools: an opportunity for oral health promotion. Bulletin of the world health organization. 2005;83(9):677-685.

2. Herijulianti E, Indriani TS, Artini S. Pendidikankesehatangigi. Jakarta: EGC; 2001.

3. Fejerskov O, Kidd E. Dental caries: the disease and its clinical management. UK: Blackwell Munksgaard: 2009.

4. Departemen Kesehatan RI. Riset Kesehatan Dasar Nasional. Jakarta: Departemen kesehatan RI; 2013.

5. Departemen Kesehatan RI. Riset Kesehatan Dasar Nasional. Jakarta: Departemen Kesehatan RI; 2007.

6. Dinas Kesehatan Kota Padang. Laporan pelayanan program kesehatan gigi dan mulut puskesmas kota Padang. Padang: DKK Padang; 2015.

7. WHO. oral health 2012 [cited 201629 Oktober]. Available from: http://www.who.int/mediacentre/factsheets/ fs $318 /$ en/.

8. Suwelo IS. Karies gigi pada anak dengan berbagai faktor etiologi. Jakarta: EGC; 1992. 
9. Widayati N. Faktor yang berhubungan dengan karies gigi pada anak usia 4-6 tahun. Jurnal berkala epidemiologi. 2014;2(2):196-205.

10. Hastuti S, Andriyani A. Perbedaan pengaruh pedidikan kesehatan gigi dalam meningkatkan pengetahuan tentang kesehatan gigi pada anak di SDN 2 Sambi Kecamatan Sambi Kabupaten Boyolali. Jurnal Ilmu Kesehatan Gaster. 2010;7(2):624-32.

11. Nurhidayat $\mathrm{O}$, Tunggul E, Wahyono B. Perbandingan media power point dengan flipchart dalam meningkatkan pengetahuan

1. kesehatan gigi dan mulut. Unnes Journal of Public Health. 2012;1(1):32-5.

12. Sari EK, Ulfiana E, Dian P. Pengaruh pendidikan kesehatan gosok gigi dengan metode permainan simulasi ular tangga terhadap perubahan pengetahuan, sikap, dan aplikasi tindakan gosok gigi anak usia sekolah di SD wilayah Paron Ngawi. Jurnal Keperawatan Unair. 2002;2(10):101-11.

13. Mashabi NAA, Djoharnas H, Darwita RR. Hubungan antara status gizi dengan karies gigi pada murid-murid di sekolah dasar Kecamatan Karangantu. Journal of Dentistry Indonesia. 2005;12(1):5-9.

14. Gunarsa SD. Dasar dan teori perkembangan anak: Jakarta; 2008.

15. Sakinatun S. Perbedaan Efek Edukasi Kesehatan Gigi dan Mulut antara Media Berbasis Komputer dengan Lembar Balik pada anak usia 7-8 tahun. [Skripsi] Jakarta Universitas Indonesia. 2013.

16. Suparno P. Teori perkembangan kognitif Jean Piaget. Yogyakarta: Kanisius; 2001.
17. Notoatmodjo S. Promosi kesehatan dan perilaku kesehatan. Jakarta: Rineka Cipta; 2012.

18. Sudono A. Sumber belajar dan alat permainan untuk pendidikan anak usia dini: Grasindo; 2000.

19. Suiraoka IP, Supariasa IDN. Media pendidikan kesehatan. Yogyakarta: Graha Ilmu; 2012.

20. Notoatmodjo S. Promosi kesehatan teori dan aplikasinya. Jakarta: Rineka Cipta; 2005.

21. Sadiman AS, Raharjo, R H. Media pendidikan pengertian, pengembangan, dan pemanfaatannya. Jakarta: PT Raja Grafindo Persada; 2005.

22. Muhson A. Pengembangan media pembelajaran berbasis teknologi informasi. Jurnal Pendidikan Akuntansi Indonesia. 2010;8(2).

23. Notoatmodjo S. Ilmu kesehatan masyarakat prinsip-prinsip dasar. Jakarta: Rineka Cipta; 2003.

24. Puskesmas Andalas. Laporan tahunan Puskesmas Andalas. Padang: Puskesmas Andalas; 2015.

25. Emzir. Metodologi Penelitian Pendidikan Kualitatif dan Kuantitatif. Jakarta : PT Raja Grafindo Persada,2010. 